\title{
Exclusion of Type 1 and Type 2 Myocardial Infarction Diagnosis Indicator
}

National Cancer Institute

\section{Source}

National Cancer Institute. Exclusion of Type 1 and Type 2 Myocardial Infarction

Diagnosis Indicator. NCI Thesaurus. Code C119237.

An indication as to whether type 1 and type 2 myocardial infarction is excluded as a diagnosis. 